\title{
Rectal Sarcomatoid Carcinoma
}

National Cancer Institute

\section{Source}

National Cancer Institute. Rectal Sarcomatoid Carcinoma. NCI Thesaurus. Code C5556.

A biphasic rectal carcinoma with a spindle cell, sarcomatoid component. 